Review

\title{
Can Climate Change Trigger Massive Diversity Cascades in Terrestrial Ecosystems?
}

\section{Lee A. Dyer ${ }^{1, *}$ and Deborah K. Letourneau ${ }^{2}$}

1 Department of Biology, University of Nevada, Reno, NV 89557, USA

2 Department of Environmental Studies, University of California, Santa Cruz, CA 95064, USA; E-Mail: dletour@ucsc.edu

* Author to whom correspondence should be addressed; E-Mail: ldyer@unr.edu; Tel.: +1-775-784-1360.

Received: 3 May 2013; in revised form: 8 June 2013 / Accepted: 13 June 2013 /

Published: 5 July 2013

\begin{abstract}
We summarize research on diversity and trophic interactions under a trophic cascades model that is reframed and expanded from the traditional biomass- or abundancebased indirect effects and discuss the response of such "diversity cascades" to climate change and other global change parameters. The studies we summarize encompass dynamic processes in which species richness or evenness in one trophic level indirectly affects or is affected by changes in a non-adjacent level. The diversity cascade concept explicitly links trophic cascades models to the debates about biodiversity loss, exotic species gain, ecosystem services and biological control. First, we summarize the idea that the trophic cascades model includes different currencies and alternative processes. Second, we question the paradigm that trophic cascades weaken as the complexity of the community increases. Third, we illustrate the mechanisms by which diversity cascades may follow indirect bottom-up and top-down pathways. Fourth, we show how this diversity cascades model has been applied successfully to frame questions in conservation, agriculture and infectious disease. Finally, we examine the implications of diversity cascades for our understanding of how climate change affects biodiversity and call for an increase in the scope of experiments and focused hypotheses on indirect trophic effects and how these processes may lead to very large changes in biodiversity.
\end{abstract}

Keywords: diversity cascades; climate change; interaction diversity; species richness; species evenness; indirect effects; top-down; bottom-up 


\section{Introduction}

Understanding the causes and consequences of large-scale changes in biotic diversity, especially in response to climate change, is one of the most important and difficult goals in the sciences today [1] and is particularly relevant to tropical ecosystems [2-4]. This daunting task will call upon the whole gamut of ecological studies, which have progressed over past decades from a focus on individual populations to studies of multitrophic interactions [5-7] to research on indirect trophic effects of resources and consumers [8,9], including non-consumptive effects, such as behavioral changes that lead to altered predator-prey dynamics [10]. Documenting diverse direct and indirect interactions within communities is similarly challenging, but is also relevant to important basic and applied issues in ecology [11-15]. We argue that the relationship between diversity and indirect trophic interactions has been underappreciated. Our goal is to further promote a shift in terrestrial trophic cascades research that expands its applicability to critical studies on biodiversity, especially in tropical ecosystems.

\section{Cascading Effects Involving Diversity Parameters}

The trophic cascade concept, first proposed by Hairston et al. [16], has provided a valuable conceptual framework for community ecology. The definition of a trophic cascade is a measurable increase in primary productivity, due to the negative effects of predators on herbivore biomass [17-19] - the trophic cascades model posits that the world is green because predators keep herbivore populations from outbreaking to levels that would cause biologically significant reduction in plant biomass. Biomass of primary producers and of consumers is the "currency" (or parameter) that is measured in empirical tests of these models, yet there are other potential currencies, such as changes in consumer behavior, altered plant physiology and modifications of species assemblages. For example, in order to focus on species diversity at different trophic levels, we previously defined a "diversity cascade" as an indirect effect that causes or is a consequence of a change in diversity on a non-adjacent trophic level [20] (Figure 1). In addition to the biomass of species found on a particular trophic level, diversity also includes the number of species at a trophic level (richness) and the relative distribution of biomass among the different species at that trophic level (evenness).

Trophic cascades can be categorized as "density-mediated indirect interactions" (DMII), while indirect effects involving other parameters, such as changes in herbivore behavior, are termed "trait-mediated indirect interactions" (TMII); although the majority of trophic interaction research has focused on DMII, some authors argue that TMII are far more important [21]. We agree with this assessment [20] and categorize diversity cascades as a special case of TMII, given that diversity is a unique trait of a given trophic level in a specific community. A focus on these other parameters, such as behavior and diversity, is important, because using only biomass as the metric of the trophic cascades model homogenizes trophic levels in a way that reduces the usefulness of the trophic cascades concept for addressing theoretically rich and globally urgent questions about biodiversity.

Trophic cascades studies, especially those categorized as DMII, have also tended to describe or explain static communities rather than to analyze dynamic processes within communities. We urge tropical ecologists to question the limitations of the traditional trophic cascades hypothesis and to consider expanding its metrics, scope and descriptive nature. For example, most diversity studies 
characterize specific communities by using richness (the total number of species) or with a diversity index, without acknowledging that these parameters can vary by orders of magnitude with temporal, spatial or biotic changes experienced by that community. By maintaining the concept of indirect trophic effects, but incorporating measures of diversity and community composition and recognizing that biodiversity is not static, but a dynamic variable, we will have a powerful tool for understanding the causes and consequences of changes in biodiversity. To this end, we have explored the diversity cascade model in empirical studies [20], and we examine further possibilities for this model as a way to understand tropical diversity. Such changes in species richness and evenness, as indirect effects propagated over non-adjacent trophic levels, driven by consumption, behavior or other traits, have been documented in a wide variety of studies (reviewed and modeled by [22-25], but cases of diversity cascades have rarely been reviewed specifically or defined formally, either via verbal or mathematical models. We focus primarily on terrestrial systems here, while Hillebrand and Shurin [26] reviewed diversity cascades in aquatic systems.

Figure 1. Selected diversity cascades. Double headed arrows indicate positive or negative effects of one variable on another. The letters next to the lines could be path coefficients or any effect size statistic. Perturbations could include changes to resources or upper trophic levels with a subsequent effect on the richness or evenness of predators or plants, respectively; perturbations could also be introduced to other trophic levels [27]. Paths going via D-C-B (including E) are bottom-up diversity cascades. For example, Pearson and Dyer [28] demonstrated that increased plant richness in grasslands leads to greater diversity of herbivores (C1), subsequently supporting higher diversity of carnivores (B1). Paths proceeding via A-B-C (including E) represent some of the possible top-down diversity cascades. Schmitz [29] showed that the presence or absence of a particular predator (A1) determined feeding patterns by herbivores on plants (B), thus strongly altering plant evenness patterns (C2). Several other possible diversity cascades (e.g., pathways from enemy evenness to plant diversity) are not depicted here.

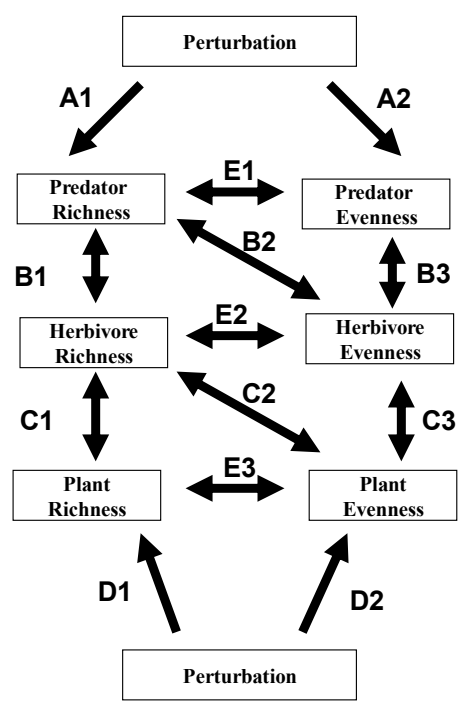

Diversity cascades as a concept directly links trophic cascades and biodiversity questions [26,27]. The approach of using diversity parameters as drivers or response variables on non-adjacent trophic 
levels differs from the concepts and syntheses presented by other authors [8-10], who examined density and trait-mediated indirect effects in interaction webs (sensu [9]) of different diversities rather than examining indirect effects involving diversity changes within an individual food web. Whereas none of the nine types and 83 subtypes of indirect effects on populations within interaction webs identified by Menge [9] can be considered diversity cascades, most of the 83 subtypes could be reexamined using richness or evenness within and among trophic levels. Because diversity cascades involve trophic levels, one can test for diversity cascades in a single ecosystem $[28,30]$ or smaller unit, such as a mesocosm [20], whereas the interaction web approach is comparative across ecosystems [9,31] or experiments [32]. Determining the specifics of diversity cascades within an ecosystem is critical for predicting or assessing the full extent of responses to perturbation and of non-intuitive outcomes. Both comparisons of population size in communities that differ in species diversity [9] and studies of indirect diversity effects within an ecosystem [33] can resolve underlying mechanisms responsible for different levels of richness, evenness and biomass within and between ecosystems.

\section{Cascading Effects in Tropical, Terrestrial Systems}

Based on extensive empirical evidence, the trophic cascades model has been accepted as a mechanism for structuring aquatic systems [19]. In contrast, arguments against the importance of trophic cascades in terrestrial systems [34-39] have helped generate the prevailing opinion that cascades weaken when moving along a gradient from simple to more complex ecosystems, such as moving from agricultural to natural or temperate to tropical ecosystems [27]. These categorical generalizations may be oversimplifications, given the paucity of true tests of their validity in terrestrial systems [27]. In addition, terrestrial systems that do not show cascading effects when adhering to a strict, biomass-based assessment may exhibit diversity cascades when reexamined with data on species richness, evenness or composition [27,40].

Although community-level perturbations do cause the removal or strong suppression of entire trophic levels in some terrestrial communities [41], as predicted by classic trophic cascades hypotheses, direct or cascading changes in species richness or evenness are likely to occur more frequently in complex systems [42]. A growing number of traditional trophic cascades studies [39,43-45] and the growing body of diversity-ecosystem function research [46,47] have underscored the contributions of complex species interactions to indirect effects on primary productivity, which is often positively correlated with plant diversity. A wide range of factors, from population densities to community parameters, such as species richness, or complex variables, such as behavioral traits and evolutionary trajectories, have provided a broader view of indirect effects, which may lead to different conclusions on their prominence in terrestrial systems $[10,21,48]$. Because diversity and biomass are not always positively correlated (e.g., $[15,20,22]$ ), the residuals in any diversity-biomass relationship may provide some of the most interesting mechanisms by which diversity cascades proceed.

Diversity cascade hypotheses do not generate some of the simple, appealing predictions of Hairston et al. [16] or the ecosystem exploitation hypothesis (EEH) [49], such as the concept that odd versus even numbers of functional trophic levels are associated with lush (i.e., little herbivory) versus barren (i.e., continual herbivore outbreaks) habitats, respectively. A broad definition of diversity cascades requires that the goal of diversity cascades research be to examine which pathways are 
important and what factors make them important. Hunter and Price [50] recognized that species identities and environmental variation are determinants of community structure and dynamics, and these determinants are as important as the number of trophic levels in a system or its location along a resource gradient [49,51-54]. Diversity cascades are more likely to cause or result from emergent and contingency effects that are different from effects predicted from models that treat trophic levels as homogeneous forces completely determined by their biomass. Key components of diversity cascades are, in fact, the elements of heterogeneity among individuals and species within and among trophic levels. These factors include varied feeding preferences, uneven consumption rates, omnivory, relative competitive abilities, foraging modes, degrees of resource supplementation-the same drivers predicted to halt traditional trophic cascades in terrestrial systems. We examine examples in the following sections of how such factors allow for indirect effects in biotic communities. Rigorous examinations of diversity cascades hypotheses will provide more insight into the impact of changes in interaction diversity, such as the community-level causes and consequences of additions (invasion, restoration, conservation), deletions (extirpation, extinction) and changes in the relative abundance among species. Here, we focus on indirect effects that are likely to be important in all terrestrial communities.

\section{Bottom-Up Diversity Cascades}

The most straightforward diversity cascade involves the indirect effect of plant richness on carnivore richness via increased herbivore richness (Figure 1) -increases in plant species cause increases in diversity at upper trophic levels. This bottom-up cascade hypothesis is well tested, with results indicating that plant diversity usually explains a biologically significant portion of consumer diversity for many different ecosystems, study taxa and scales of study [55-57] (but, see [58]). There are both evolutionary and ecological components to the hypotheses explaining high positive plant-animal diversity correlations, but the bottom-up diversity cascade is a strictly ecological phenomenon. The ecological mechanism for this cascade relies on the colonization of more species of herbivores in communities with higher plant diversity and more species of predators in communities with higher prey diversity; such increased colonization in model communities relies on a combination of greater niche space and consumer resource partitioning when resource diversity is high [59-61].

Brändle and colleagues [62] found that calcareous emissions, which improved soil quality near the source, resulted in a concomitant gradient in plant species richness that tapered off with distance. The richness of specialist herbivores was positively correlated with plant richness, but herbivore abundance was not. Finally, while carnivore richness was positively associated with herbivore richness, it did not follow the resource gradient (i.e., it was correlated with the resource-herbivore richness residuals). This system did not include an actual bottom-up trophic cascade, because direct effects were present, but indirect effects along the resource gradient were absent; nevertheless, the pattern of cascading diversity indicates that resource deposition created a spatial mosaic of species assemblages that varied in species richness. Thus, measurements of quantitative changes (productivity, biomass) alone do not detect the complex dynamics occurring in perturbed systems and may not provide the appropriate empirical data needed to develop a theory for trophic ecology, which forms the critical basis for community-based conservation, restoration and biological control. 
Whereas biomass augmentation cascading to higher trophic levels can be explained by enhanced energy and nutrient resource availability for consumers, the mechanisms driving cascading changes in species diversity parameters are less well understood. As a hypothetical example, a community with enhanced plant species richness may be expected to show a traditional bottom-up cascade if plant biomass (productivity) is increased, but a diversity cascade in the same community results from emergent interactions among species; carnivore diversity changes could depend on whether the new plant species are native or exotic or if the plants are palatable or well-defended against herbivores.

Plant community attributes other than diversity can also cascade up through their effects on herbivores to affect diversity parameters (e.g., richness, evenness) of carnivores or to affect interaction diversity. Empirical examples of other plant community attributes indirectly affecting diversity at upper trophic levels include changes in plant quality [63] and increased architectural complexity [64]. In alfalfa fields, some of the variability in carnivore diversity was explained by an increase in plant diversity in fertilized plots, but a stronger bottom-up effect occurred in response to changes in plant quality (higher saponin content), which caused increases in herbivore evenness and a subsequent increase in carnivore richness. The proposed mechanism for this change was that specialized herbivores adapted to saponins increased in abundance compared to generalist herbivores, providing an emergent increase in the richness of natural enemies [63]. In a tropical ecosystem, the addition of fertilizer in communities dominated by Metrosideros polymorpha increased not only the abundance, but also the number of herbivore and carnivore species per unit of plant biomass [65]. Increased nutrient resources were associated with more species of specialized, native herbivores on these trees. In a simple case of architectural complexity potentially cascading up to cause high predator diversity, carabid beetle communities are more diverse when spruce stands have a well-developed understory layer, reducing the dominance of a single species [64]. Additional plant characteristics that act as drivers of indirect effects on carnivore diversity include: plant biomass [66,67]; plant genetic diversity [68,69]; plant geographic distribution and apparency [70]; fungal mutualism/plant defense [71]; and, perhaps, plant ontogeny [72]. A common process in these examples of bottom-up diversity cascades is a positive consumer response to higher quality or complexity of resources (as opposed to higher resource abundance [73]). Because species pool size can act as a limiting factor in species accumulation, such diversity cascades may be facilitated rather than inhibited by community complexity, including omnivory.

\section{Top-Down Diversity Cascades}

Interactions among species and factors, such as omnivory, diet breadth and dominance, can be critical to top-down diversity cascades, because the effects of consumers on resources can be positive or negative, depending on the particular assemblage of species [74]. For example, an increase in predator diversity can cause an overall increase in herbivore abundance, due to greater intra-guild predation [75,76], which, in turn, can cause decreases in plant evenness or in total plant biomass (Figure 1). On the other hand, increased enemy diversity may be just as likely to cause decreases in herbivory if the enemies are more specialized, such as parasitic Hymenoptera. In this case, either complementarity between predators or just a sampling effect (i.e., the most effective predator is more likely to be sampled from a larger sample of enemies) causes an increase in overall enemy-induced mortality of herbivores [77]. For cascading effects of enemy diversity that results in increased plant 
productivity or yield, whether it is due to complementarity or sampling effect, an effective assemblage usually involves the inclusion of more species of specialized predators and parasites or a shift in evenness reflecting an increase in their relative abundance.

Otto and colleagues [78] manipulated access by predators, including two specialists, on willow-feeding beetles. In this case, high predator diversity led to higher levels of plant biomass through a decrease in herbivore survivorship and biomass. The primary mechanism contributing to this diversity cascade in willow was the lack of overlap in predator phenology, which resulted in an increase in natural enemy evenness over time - a subtlety that would not be captured in biomass measurements of carnivores. In another system, predator diversity manipulations using three generalist coccinellid beetle species showed that interference competition among the predators reduced per capita rates of aphid predation and, in turn, the overall efficiency of the predator guild [79]. In this case, increased predator species richness caused greater resource (aphid) availability, which, in turn, caused greater predator species richness and evenness, in response to high density patches of aphids. In contrast, the combination of a generalist coccinellid beetle with a generalist damsel bug and a specialist parasitic wasp suppressed aphids more than the levels expected from summing the effects of each species alone [80]. The mechanism by which higher predator richness had greater community effects involved generalist enemies reducing the density of cowpea aphids, which would have otherwise interfered with parasitism of pea aphids by their specialist parasitoid.

Schmitz $[81,82]$ suggested that weak effects of top trophic levels on aggregate measures of plant biomass can occur at the same time as stronger community level effects on plant diversity. When three functional trophic levels were allowed to operate in the community, the abundance of key herbivores was affected less than the relative abundance of foraging herbivores, as key species sought refuge from hunting spiders. In the presence of spiders, grasshoppers hid in goldenrod, feeding disproportionately on that plant species, reducing its competitive dominance in the community and increasing overall plant evenness. Dyer and Letourneau [20] also illustrated how the same system can be described differently, depending on which definition of trophic cascade is used. A diversity cascade occurred when the addition of a predatory beetle that specialized on a dominant ant species caused an increase in the diversity of predacious ants living in a tropical understory shrub. This increase in ant diversity was associated with a lower diversity of herbivores, but overall higher levels of herbivory and lower plant biomass [20]. These results, viewed originally as a density-mediated cascade $[83,84]$ through four trophic levels or as a species cascade [36], can be viewed just as reasonably as a diversity cascade by simply switching the focus from the biomass of one predatory ant (Figure 2, A2-B3-C3) to the species richness of associated ants (Figure 2, Path A2-E1-B2-C3). A switch in the nature of the food supplement for ants in this case, in which the majority of ant species in this system forage off the plant, resulted in lower consumption of herbivores on the plant, facilitating the indirect effects on plant biomass. Additionally, Letourneau and colleagues [85] demonstrated that apex predator addition changed plant species richness in surrounding understory, with the outcome depending on soil quality.

Top-down and bottom-up indirect effects often work together to produce strong diversity cascades. A good example of this was presented by Eveleigh and colleagues [67], who used long-term datasets and manipulative experiments to demonstrate that the parasitoid communities associated with spruce budworm may exhibit a bottom-up diversity cascade. Higher regional host plant richness can create variation in budworm densities, allowing for a "birdfeeder effect" (local prey surges attract regional 
predators) and increases in enemy richness for the third and fourth trophic levels. This increase in diversity at upper trophic levels caused a dampening of budworm outbreaks, indicating both bottom-up and top-down consequences of this diversity cascade. The authors pointed out that the food-web changes in diversity should be a potent stabilizing mechanism and that the changes were greater in heterogeneous than in homogeneous forest plots (but, see [85], in which community stability is assessed as resistance to a diversity cascade). The Eveleigh study [67] demonstrates part of a general mechanism, where plant composition, biomass or diversity can be altered by apparent competition among herbivores [86]. That is, the relative abundance of some herbivores depends on the relative abundance of natural enemies that are supported by another herbivore or set of herbivores.

Figure 2. Diversity cascades in a tropical forest based on patterns uncovered by experiments and observational data $[20,83,84]$. Bullet-heads indicate a negative effect of an increase in one variable on another. One diversity cascade depicted here (A2-E1-B2-C3) involved the increased dominance of a top predatory beetle that caused decreases in predatory ant dominance (A2), indirectly decreasing ant richness (via E1), decreasing herbivore evenness (via B2 and B3) and decreasing leaf area of one understory plant species, decreasing plant evenness (via C3). Another top-down diversity cascade in this system involved the same top-down effects, which resulted in increases in plant diversity on poor soils (via E3).

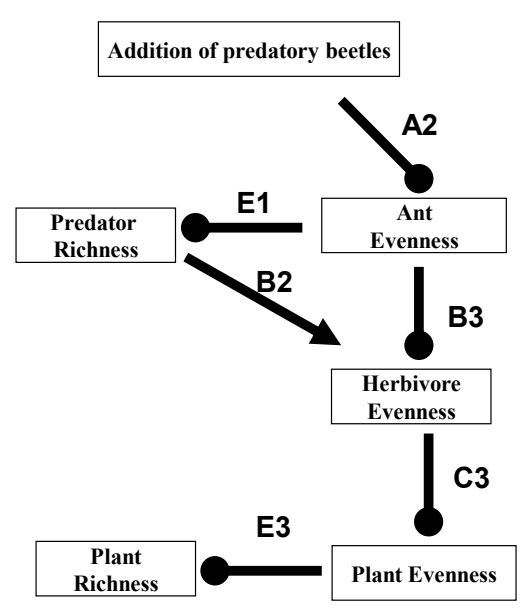

\section{Summary of Mechanisms}

How do richness and evenness indirectly affect other trophic levels or change indirectly by perturbations elsewhere within the food chain? Although there are many potential pathways and underlying mechanisms that can occur and be categorized as diversity cascades, there are some that appear to be more common than others, based on meta-analyses [33,74,87], reviews [88] and the papers we have reviewed here (Figure 1). The strongest diversity cascades for which diversity is the manipulated variable are analogous to the traditional trophic cascade-increases in richness or evenness of predators on the third trophic level cause reduced levels of herbivory and higher plant biomass and productivity [26,33]. The dominant mechanisms examined thus far for this top-down diversity cascade have been uncovered via agricultural research and include the lottery, insurance and additive effects, all of which are caused by species complementarity and multiple functional groups of 
predators $[30,74,80,89-92]$ - for these mechanisms, the appropriate mix of predators are present to control populations of any herbivore guilds. As evenness or richness of carnivores increases, the total amount of niche space occupied also increases, resulting in greater reductions of herbivores. Thus, for the additive (or "cumulative stress") model of plant biological control, the effects of additional enemy species are additive and can control lower trophic levels by pushing populations below some threshold. For the lottery model, larger predator assemblages are more likely to suppress prey/host populations, simply because the probability of sampling the "right" enemy is increased. Furthermore, for insurance effects, higher richness or evenness insures that sufficient numbers of predators in key functional roles are available to suppress herbivores [33].

There are certainly other mechanisms that are responsible for indirect positive effects of predator diversity on plant biomass, but another that deserves mention, despite being under-investigated, is facilitation [93-95]. Some enemies may create conditions that are favorable for other enemies, allowing for more efficient regulation or depletion of herbivores. For example, parasites of snowshoe hares make them more susceptible to predation by owls and mammals [96], causing destabilization of hare-predator population dynamics. This is similar to the role of parasitoids in insect food webs, when they change the behavior of caterpillars, making them sluggish and disrupting primary and secondary defenses, such that they are easier prey items for most vertebrate and invertebrate predators [97]. In these cases, higher richness and evenness will allow for greater facilitation via increasing interaction diversity and opportunities for facilitation.

The strongest cascades for which diversity is the response variable are bottom-up cascades, with plant diversity driving consumer diversity at upper trophic levels (Figure 1); these bottom-up diversity cascades have been clearly demonstrated from both natural and agricultural systems (see above). The mechanisms for these cascades have been reviewed in other papers [50,98]-more diverse resources for consumers provide more niche space and more opportunities for specialist herbivores and carnivores. Related studies that examine the indirect effects of changing resource quality on diversity of upper trophic levels is useful in displaying these mechanisms. This is well illustrated by Bukovinszky and colleagues [99], who revealed that variation in Brassica quality caused variation in aphid size, which, in turn, supported different sizes and higher species richness of primary parasitoids and increased secondary parasitoid richness and evenness (Figure 3). In this case, a comparison of two food webs demonstrated that cascading effects from plant resource quality to fourth trophic level species richness involved differently sized resources, but it illustrates the same mechanisms in terms of niche heterogeneity.

Top-down diversity cascades affecting plant richness or evenness have not been well tested, but it is likely that the mechanisms for predator biomass mediated cascades are the same as those responsible for diversity cascades: higher diversity of top consumers prevents competitive dominance of individuals at lower trophic levels, resulting in greater richness and evenness [100]. Finally, the effects of richness and evenness on one another can be embedded in any diversity cascade. For example, a shift in herbivore communities dominated by leaf-cutter ants, due to the loss of predators, resulted in decreases in bird diversity on land-bridge islands in Lago Guri, Venezuela [101] (Figure 4). In contrast, for islands that had increases in monkey herbivory in response to loss of predators, a greater evenness of herbivore communities is one potential reason for the greater bird diversity on these islands (Figure 4). 
Figure 3. The ecological meltdown demonstrated by Terborgh and colleagues [41] was a strong demonstration of a trophic cascade - tropical islands without vertebrate predators experienced very low productivity, due to outbreaks of herbivores, such as leaf cutter ants. This system could also be reexamined as a diversity cascade, since enemies of herbivores, such as phorid flies, are still present on all islands, and the herbivore and plant communities are diverse webs. Another study on this same system of islands [101] demonstrated that the islands with missing vertebrate predators had herbivore communities dominated by leaf-cutter ants (lower overall evenness of herbivores, B1), while islands with higher richness and abundance of predators had higher evenness in herbivore communities (balanced between howler monkeys and insects). This change in herbivore diversity was associated with lower plant productivity (potentially caused by pathway $\mathrm{C} 1$ ), which was partially responsible for decreases in overall bird diversity (via C2) on the low predation islands.

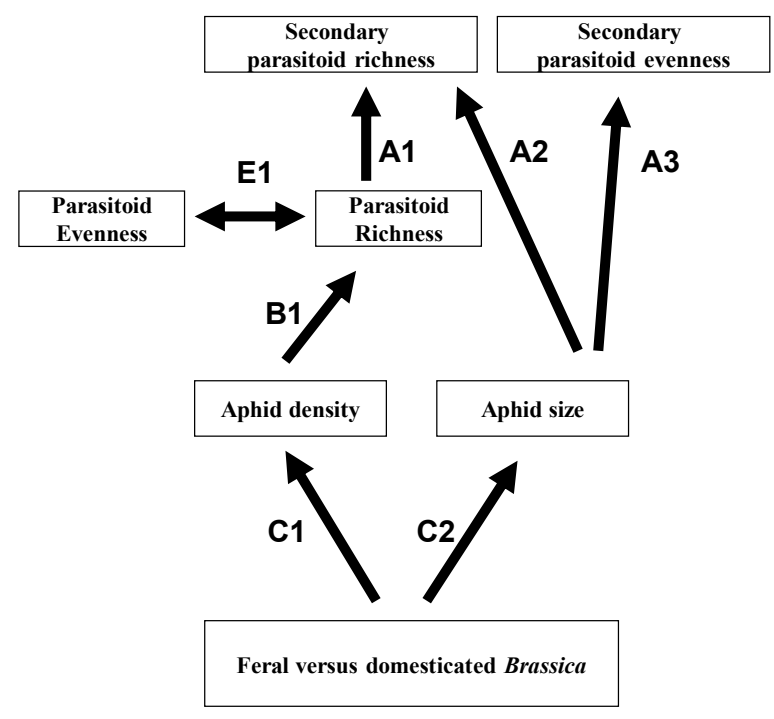

Figure 4. A bottom-up diversity cascade in an insect food web [99]. In this system, plant quality affected aphid size and density, which had direct and indirect effects on parasitoid and secondary parasitoid richness and evenness. The diversity cascade represented by the pathways $(\mathrm{C} 1, \mathrm{~B} 1, \mathrm{~A} 1)$ is one example of the strong effects of subtle changes in resource quality that can accompany changes in plant diversity. Not all measured effects from the study are shown in the diagram.

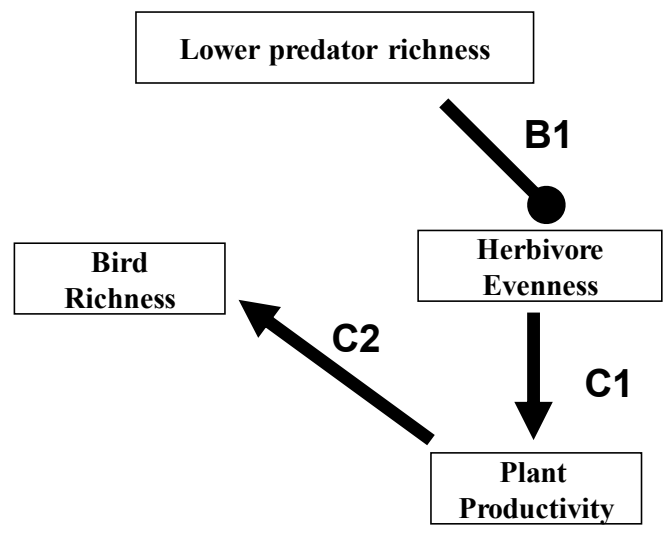




\section{Relevance to Agriculture, Conservation and Emerging Infectious Disease}

The traditional trophic cascades hypothesis [16] was, conceptually, the backbone of contemporary biological control efforts in agriculture and had valuable applications in arguments against predator control and poaching in ranching and wildlife reserves, as well as in later campaigns against overfishing. However, complementary work regarding diversity cascades took up where applications of theory about homogeneous biomass effects of trophic levels left off. For example, Root's enemies hypothesis [102] spurred decades of research on intercropping, predicting bottom-up diversity cascades and subsequent top-down effects on pests in diversified agricultural systems. Both direct effects of vegetational diversity on herbivore communities and indirect effects on carnivore levels have been demonstrated commonly and can improve pest control [87,103]. The search for appropriate predictions, such as determining the biotic and abiotic conditions under which indirect effects involving species richness and evenness are likely to occur, is relevant to applied issues in conservation, agriculture, ecology of disease and (discussed in the next section) climate change.

Agricultural habitats are practical experimental ecosystems to use in testing predictions of diversity cascade hypotheses. For example, a number of studies have demonstrated that decreased diversity at the third trophic level in agriculture can have potentially negative [104-110] or positive [80,90,111] indirect effects on crop production. It is a priority for biological control to determine which conditions cause a negative versus positive diversity cascade from parasitoids and predators to crop yield [112]. Recent attention to changes in dominance and evenness, as well as species richness within a trophic level are providing insights to derive a better theoretical framework for diversity cascades [42]. Increased species richness or evenness of natural enemies, which can emerge from the relative abundance of herbivores [113], richness of herbivores [114], plant species richness [115] or other factors, such as decreased habitat fragmentation [105], can result in improved crop yields. An elegant study by Crowder and colleagues [33] shows that for a given number of species, an increase in natural enemy evenness increased crop biomass. Letourneau [116] borrowed the concept of "ecological extinction" from conservation biology to explain how a reduction in relative abundance of some natural enemies compared to others can reduce functional interconnectedness in agroecosystems.

Hillebrand and colleagues [42] encourage further attention to changes in dominance and evenness, which occur commonly in response to human-proffered perturbations from exotic species introductions to global warming and likely precede species extinctions. Their review indicates that the strength and direction of bitrophic diversity effects vary with respect to various biotic and abiotic factors and that shifts from equitable representation among species to dominance can increase or decrease ecosystem function. Developing attention to diversity within and among trophic levels will lead to the discovery of indirect effects, as well as a clarification of mechanisms involving adjacent trophic levels.

In conservation, the diversity cascade concept has been used to try to predict indirect consequences of species extinctions [73]. It is clear that the effects of extinctions can cascade through trophic levels and impact "ecosystem function" or other metrics used by conservation biologists. Although indirect effects of extinctions are difficult to predict, Srivastava and Vellend [73] acknowledge that it is important to understand how losing a single species might have consequences for other species and associated conservation goals. Sinclair and colleagues [30] discuss clear conservation implications of a diversity cascade, due to reductions in predator richness in one of the world's premier conservation areas, the 
Serengeti. These authors examined long-term data sets of vertebrate herbivores along with long-term mensurative experiments (hunting of predators in selected areas). Their data show that a less diverse predator fauna results in dramatic increases of selected herbivores, decreasing herbivore evenness, which the authors predict would eventually lead to outbreaks and extinctions of other herbivores via changes in plant resources. In this system, the top-down diversity cascade consists of a lower diversity of predators, leading to outbreaks of smaller herbivores (e.g., zebra and wildebeest), and, then, resource limitation for the larger herbivores (e.g., rhino and hippo). Ale and Whelan [117] review indirect effects of apex predators through mesopredator release and illustrate the importance of trait-mediated diversity cascades in directing conservation efforts.

Recent studies have linked this genre of conservation concerns (e.g., loss of predator diversity) to the ecology of infectious disease, highlighting the human health consequences of biodiversity loss [118]. Many of these studies have demonstrated clear top-down diversity cascades-where declines in predator diversity lead to an increase in host density and a subsequent (indirect) increase in infectious vectors and disease. For example, in Kenya, habitat disturbance led to lower diversity of mosquito predators directly (Figure 1, A1-B1) and indirectly via reduction of native mosquito richness (Figure 1, A1-B1-E2). This resulted in increased dominance of Anopheles gambiae, the primary malaria vector in Africa, which was historically absent from the highlands. The overall diversity cascade causing decreased evenness of mosquitoes partially explains the emergence of malaria in the Kenyan highlands [119]. In the eastern U.S., the incidence of Lyme disease is negatively correlated with the species richness of small mammal hosts, which vary widely in their ability to carry the disease, and correlates positively with the species richness of bird hosts, many of whom are good reservoirs [120]. LoGiudice and colleagues [121], however, point out the importance of species identity in these dynamics, which may further illustrate the mechanisms involved in diversity cascades.

\section{Climate Change and Biologically Significant Diversity Cascades}

Ecologists are making progress towards understanding the effects of rapid changes in climate and biogeochemical cycles on trophic interactions and diversity, and the effects of climate parameters on diversity via direct plus indirect pathways indicate that diversity cascades in response to specific climate change variables will be very large [122-137]. There are fewer studies that manipulate or measure the interacting effects of changes in multiple climate parameters, such as precipitation, temperature and $\mathrm{CO}_{2}$, on species interactions or diversity cascades [138-144], and the theoretical framework for studying climate change and diversity cascades or even direct biotic interactions is underdeveloped [122,145-147]. What insight do the existing studies provide to help understand the potential effects of interacting global change parameters on diversity cascades? Increases in temperature and atmospheric $\mathrm{CO}_{2}$ interrupt the relationships between plants, plant chemistry, herbivores and their associated enemies through complex mechanisms [127,130,142,148]. It is clear that there will be strong top-down effects on diversity by direct changes to herbivore and natural enemy development and survival that can facilitate large decreases in plant richness and evenness (Figure 1, C1, $\mathrm{C} 2$ and $\mathrm{C} 3$ ). For example, high temperatures, higher atmospheric $\mathrm{CO}_{2}$ and extreme weather events all have direct negative effects on survival of parasitoid wasps [124,127,149], which are extremely important sources of mortality for insect herbivores [97]. As a result of these negative 
effects on parasitoids, insect herbivore outbreaks can increase [150], causing decreases in herbivore evenness and subsequent decreases in plant diversity. Any such interactions between multiple climatic variables are likely to contribute to very large effect sizes (e.g., using Cohen's statistical effect size categories). For example, this was the case for the combined negative effects of $\mathrm{CO}_{2}$ and temperature on alfalfa chemistry and biomass via synergistic increases in developmental asynchrony between parasitoids and herbivores, favoring the herbivores [151]. When combined with the effects of extreme weather events [150], these effects are likely to synergize even further and will be particularly severe - such synergies between direct and indirect effects could be described as "massive" or any similar adjective that captures large statistical effects.

The direct effects of climate change variables on plant quality, biomass and diversity have been quantified in other reviews or empirical studies [151,152]. For example, elevated $\mathrm{CO}_{2}$ increases plant growth directly by increasing photosynthesis and indirectly by reducing plant quality for herbivores [151]. These changes in plant quality have variable effects on herbivore performance, but the end result is a change in consumer-resource dynamics, causing shifts in richness and evenness of herbivores, which can cascade both upwards and downwards (Figure 1). The studies that have examined the effects of climate change on tritrophic interactions suggest that effects on these interactions will favor outbreaks and (in some cases) associated decreases in diversity in natural and managed ecosystems, including most agriculture [151]. Probably the most important of the climatic changes for triggering massive diversity cascades will be increases in climatic variability and extreme weather events associated with climate change, because they disrupt regulation of herbivores by predators and parasitoids [124,127,150], leading to large shifts in herbivore and plant diversity. Many questions remain about how diversity cascades might intensify in response to changes of multiple climatic variables, but the following effects are clear: (1) abundances of pest herbivores will increase, due to higher temperatures; (2) increases in extreme weather events will lead to disruption of normal pest control by natural enemies; (3) carbon-based plant defenses will increase in response to warming and enhanced $\mathrm{CO}_{2}$; and (4) additional, unpredictable patterns of diversity change will emerge, due to cascades and synergies [151,152]. Thus, it is a worthwhile goal to conduct research related to the general hypothesis that climate change will trigger massive diversity cascades.

\section{Future Directions}

The focus of diversity cascades research should be on utilizing a combination of the best available methods to create a broader synthesis and an improved understanding of mechanisms behind cascades. For understanding the effects of multiple climate change variables on diversity cascades, one approach is to conduct experiments on simple tritrophic systems and to include manipulations of multiple variables that are changing globally, allowing for tests of specific hypotheses about how climate change can dramatically alter diversity cascades. More such experiments, coupled with large-scale observational data and models, will help clarify the conditions under which factors, like connectance, parasitism, herbivore, outbreaks and ecosystem services, will increase or decrease in response to interacting climate change variables. Ecologists should certainly avoid short-term experiments with spatial scales that fail to rigorously test the relevant hypotheses, are often contradictory and yield few theoretical advances. Here, we propose hypotheses relevant to diversity cascades and provide 
recommendations for approaches to testing these and related hypotheses. For all of these hypotheses, we echo Hunter and Price [50] in suggesting that an integrated approach is likely to produce a better synthesis for advancing trophic cascades theory. Rather than conducting disparate small-scale and short-term experiments, ecologists should utilize an integration of all available tools, including models $[153,154]$, detailed natural history observations [155], correlational approaches [84] and tractable systems, such as islands [156] or mesocosms [27]. The examples of diversity cascades that are reviewed here and elsewhere are primarily in temperate systems. Utilizing the approaches below, it is likely that tropical ecologists will uncover important diversity cascades pathways in natural and managed systems that are characterized by high interaction diversity and that are likely to be altered significantly by global change.

\section{Hypotheses}

Based on the numerous studies in natural and agricultural systems that have indirectly documented diversity cascades, these indirect effects appear to be common in complex ecosystems and are facilitated by factors thought to buffer traditional trophic cascades. The representative studies we have reviewed here include results from a variety of ecosystems, including aquatic, terrestrial, natural, agricultural, temperate and artificial (e.g., mesocosm) ecosystems. It is likely that the central role of diversity cascades will be revealed through more studies or through re-visiting traditional trophic cascades studies, to examine the indirect effects of changes in species richness and relative abundance (dominance or evenness) at a given trophic level. For example, the classic study of the snowshoe hare cycles demonstrates a trophic cascade via reducing predator richness-excluding lynx, coyotes and other mammalian predators, but not excluding raptors, owls or smaller enemies [157]. The dramatic effects of this change in predator diversity on hare populations and overall plant biomass are well documented, as are many of the mechanisms of the direct and indirect effects [158]. Similarly, Terborgh and colleagues [41] found that islands formed by hydroelectric impoundments in Venezuela had low predator richness compared to the mainland and experienced levels of herbivory 10 to 100 times greater than comparable areas on the mainland with corresponding reductions in plant seedlings and saplings. Both of these well-cited examples of a trophic cascade caused by changes in predator diversity could be further examined as direct tests of diversity cascades hypotheses by using the same experimental or observational approaches already utilized, but by measuring the changes in plant richness and evenness that likely occurred in response to large reductions of plant biomass. The real challenge will be to develop general diversity cascades theory via the appropriate modeling and empirical approaches to produce generalities about the directions of indirect effects expected under given conditions (e.g., productivity gradients, species pool limitations, shifts in generalist:specialist ratios or exotic species invasions) and to determine the extent of species identity effects. The following four hypotheses provide initial directions for developing such a theory, with the first three focused on the mechanics of diversity cascades and the fourth focused on the potential for climate change to trigger very large changes in diversity via these cascades. For these hypotheses, we make the assumption that many tropical communities have low nestedness [159], which is more likely the case for consumptive food webs $[41,158,160,161]$, but may not be the case for mutualistic webs [160]. An assumption of high nestedness may also be appropriate for temperate webs that do not feature high levels of specialization at multiple levels of organization. However, recent work has shown that two-trophic-level 
communities, including mutualisms, are not nested when interaction strength is considered [162]. Communities with high nestedness would lead to hypothesized patterns that are the opposite of those presented here.

HYPOTHESIS 1. As consumer specialization increases, the strength and directionality of diversity cascades increase. In insect food webs, which have low compartmentalization, specialist consumers tend to have greater population-level impacts on their resources (e.g., parasitoids are a greater source of mortality for lepidopteran larvae than more generalized predators [163]) and are likely to enhance top-down impacts on a community. This effect of specialists is likely to increase the intensity of standard density and traitmediated indirect effects, which, in turn, increases the likelihood of indirect effects on diversity (e.g., Figure 1, A1-B1-C1-E3). Similarly, species additions or deletions of specialist consumers or shifts in their dominance (i.e., changes in the diversity of upper trophic levels) are more likely to have strong topdown effects on communities than slight changes in the richness of generalists - for example, extinction of specialist parasitoids or dominance by generalist predators could indirectly cause decreased productivity via herbivore outbreaks.

HYPOTHESIS 2. Top-down forces are more effective at changing the diversity of communities composed of specialist herbivores, whereas bottom-up forces are more important for those dominated by generalists. While specialist predators have a greater top-down effect in communities, changes in resource quality and quantity are more likely to affect generalist consumers, which are less adapted to defenses and are more likely to colonize resource-rich environments [164]. Although natural communities are rarely dominated by specialist herbivores, some communities have higher mean specialization. For example, diet breadths of caterpillars are, on average, much narrower in tropical versus temperate forests in the Americas [161]. Thus, we hypothesize that tropical forests are more likely than temperate forests to experience top-down diversity cascades involving caterpillars. The bottom-up influence on generalists is well demonstrated by the effects of landscape heterogeneity on variation in budworm densities and increases in enemy richness for the third and fourth trophic levels [67].

HYPOTHESIS 3. The higher the interaction diversity for a given set of species, the greater the potential for diversity cascades, suggesting the weaker influence of introduced species than of native species. The number of pairwise population interactions out of all potential interactions in a community is a metric that should increase with the importance of diversity cascades, simply because all of the pathways in a diversity cascade (Figure 1) depend on strong pairwise interactions between trophic levels. Interaction diversity (or its related variable, connectance) is not always positively correlated with species richness or resource generalization; thus, this hypothesis is unique from Hypothesis 1 and does not necessarily contradict Hypothesis 2. In contrast to the negative diversity effects of exotic species via competitive exclusion, this hypothesis predicts that the addition of non-native species (Figure 1, A1 or D1) is less likely to trigger cascades than the addition of species that are involved in strong pairwise interactions. This prediction is a cornerstone of classical biological control, which focuses on importing exotic enemies of exotic pests to increase connectedness and, thus, cause more effective cascades. Exceptions that may prove the rule are most likely to involve highly dominant invaders in relatively depauperate or fragmented communities. For example, an invasive ant caused strong effects, including a diversity cascade, on a remote tropical island, where the predaceous ant 
supercolonies extirpated the primary generalist seedling herbivore and, thus, increased understory plant richness [165].

HYPOTHESIS 4. Changes in multiple climate variables may cause massive diversity cascades, leading to large swings in diversity. There are multiple consequences to the fact that the responses of biotic interactions to the climate change are complex. This includes the possibility that effects acting via different direct or indirect pathways could lead to changes not predicted by single factor models or experiments - particularly those that are additive to synergistic. For example, for rare plants in a community, increases in the biomass of superior plant competitors due to increased temperature can be exacerbated by decreases in parasitism and increases in herbivore outbreaks, such that the overall effects of temperature (direct plus indirect) on plant diversity are strongly negative. It is clear that such hypotheses must be examined in order to produce realistic predictions for future impacts of climate change on biotic communities.

\section{Conclusions}

What is the legacy of utilizing experimental approaches with one plant species, one herbivore species or one predator species doing to our understanding of how a community of many species and trophic connections responds to perturbations? In trophic cascades literature, the result is that those attempting to test classic traditional trophic cascades hypotheses were unable to do so, because what they demonstrated was, in fact, only a species cascade, meaning that for a top-down cascade, productivity of an entire community was not tested; only one plant species was affected by the manipulation. Adding the diversity cascade to tests of indirect effects in community ecology will provide a broader framework for understanding species additions and deletions to ecosystems around the world. Diversity cascades are likely to be prevalent in all ecosystems with more than two trophic levels, since the last 40 years of ecological studies have shown, among other corroborative patterns: (1) indirect effects are ubiquitous; (2) uneven consumption is common, because of prey and host specialization and due to shifts in the relative abundance among species; (3) mortality can result from consumption, even in plants; (4) trait-mediated effects and non-lethal effects can structure communities; and (5) recruitment has a stochastic element. Combining these elements with temporal and spatial heterogeneity of biotic and abiotic factors, we propose that indirect effects involving changes in biodiversity should be the rule rather than the exception. As we focus our diversity cascade hypotheses and predictions, the benefits to ecological theory, agriculture and conservation will certainly accumulate. Furthermore, our ability to predict potentially dramatic changes in biodiversity in response to a rapidly changing climate depends on a better understanding of diversity cascades.

\section{Acknowledgments}

Thanks to Mike Singer, Pedro Barbosa, Sarah Bothwell, Tara Cornelisse, Julie Jedlicka Tara Massad, Angela Smilanich, Chris Wilmers and Dan Gruner for comments on early versions of the manuscript, to anonymous reviewers and to many other ecologists for discussions on these issues. This paper was possible due to funding to LAD from NSF (DEB 1020509 and DEB 1145609) and Earthwatch Institute, as well as funding to DKL from USDA-NRI grant \#2005-0288. 


\section{Conflict of Interest}

The authors declare no conflict of interest.

\section{References}

1. Chapin, F.S., III; Zavaleta, E.S.; Eviner, V.T.; Naylor, R.L.; Vitousek, P.M.; Reynolds, H.L.; Hooper, D.U.; Lavorel, S.; Sala, O.E.; Hobbie, S.E.; et al. Consequences of changing biodiversity. Nature 2000, 405, 234-242.

2. Thompson, J.N. Conserving interaction biodiversity. In The Ecological Basis of Conservation: Heterogeneity, Ecosystems, and Biodiversity; Pickett, S.T.A., Ostfeld, R.S., Shachak, M., Likens, G.E., Eds.; Chapman \& Hall: New York, NY, USA,1997; pp. 285-293.

3. Lewinsohn, T.M.; Roslin, T. Four ways towards tropical herbivore megadiversity. Ecol. Lett. 2008, 11, 398-416.

4. Carson, W.P.; Schnitzer, S.A. Tropical Forest Community Ecology; Blackwell Publishing: Oxford, UK, 2008.

5. Price, P.W.; Bouton, E.E.; Gross, P.; McPheron, B.A.; Thompson, J.N.; Weiss, A.E. Interactions among three trophic levels: Influence of plants on interactions between insect herbivores and natural enemies. Annu. Rev. Ecol. Syst. 1980, 11, 41-65.

6. Tscharntke, T.; Hawkins, B.A. Multitrophic Level Interactions; Cambridge University Press: Cambridge, UK, 2002.

7. Singer, M.S.; Stireman, J.O. The tri-trophic niche concept and adaptive radiation of phytophagous insects. Ecol. Lett. 2005, 8, 1247-1255.

8. Abrams, P.; Menge, B.; Mittelbach, G.G.; Spiller, D.; Yodzis, P. The role of indirect effects in food webs. In Food Webs: Integration of Pattern and Dynamics; Polis, G.A., Winemiller, K.O., Eds.; Chapman \& Hall: New York, NY, USA, 1995; pp. 371-395.

9. Menge, B.A. Indirect effects in marine rocky intertidal interaction webs - Patterns and importance. Ecol. Monogr. 1995, 65, 21-74.

10. Peckarsky, B.L.; Abrams, P.A.; Bolnick, D.I.; Dill, L.M.; Grabowski, J.H.; Luttbeg, B.; Orrock, J.L.; Peacor, S.D.; Preisser, E.L.; Schmitz, O.J.; et al. Revisiting the classics: Considering nonconsumptive effects in textbook examples of predator-prey interactions. Ecology 2008, 89, 2416-2425.

11. Janzen, D.H. Deflowering of Central-America. Nat. Hist. 1974, 83, 48-53.

12. Thompson, J.N. Evolutionary ecology and the conservation of biodiversity. Trends Ecol. Evol. 1996, 11, 300-303.

13. Del-Claro, K. Multitrophic relationships, conditional mutualisms, and the study of interaction biodiversity in tropical savannas. Neotrop. Entomol. 2004, 33, 665-672.

14. Tylianakis, J.M.; Tscharntke, T.; Lewis, O.T. Habitat modification alters the structure of tropical host-parasitoid food webs. Nature 2007, 445, 202-205.

15. Dyer, L.A.; Walla, T.R.; Greeney, H.F.; Stireman, J.O.; Hazen, R.F. Diversity of interactions: A metric for studies of biodiversity. Biotropica 2010, 42, 281-289. 
16. Hairston, N.G.; Smith, F.E.; Slobodkin, L.B. Community structure, population control, and competition. Am. Nat. 1960, 94, 421-424.

17. Paine, R.T. Food webs: Linkage, interaction strength and community infrastructure. J. Anim. Ecol. 1980, 49, 667-685.

18. Power, M.E. Effects of fish in river food webs. Science 1990, 250, 811-814.

19. Carpenter, S.R.; Kitchell, J.F. The Trophic Cascade in Lakes; Cambridge University Press: New York, NY, USA, 1993.

20. Dyer, L.A.; Letourneau, D.K. Top-down and bottom-up diversity cascades in detrital vs. living food webs. Ecol. Lett. 2003, 6, 60-68.

21. Schmitz, O.J.; Krivan, V.; Ovadia, O. Trophic cascades: The primacy of trait-mediated indirect interactions. Ecol. Lett. 2004, 7, 153-163.

22. Borrvall, C.; Ebenman, B.; Jonsson, T. Biodiversity lessens the risk of cascading extinction in model food webs. Ecol. Lett. 2000, 3, 131-136.

23. Borrvall, C.; Ebenman, B. Biodiversity and persistence of ecological communities in variable environments. Ecol. Complexity 2008, 5, 99-105.

24. Petchey, O.L.; Downing, A.L.; Mittelbach, G.G.; Persson, L.; Steiner, C.F.; Warren, P.H.; Woodward, G. Species loss and the structure and functioning of multitrophic aquatic systems. Oikos 2004, 104, 467-478.

25. Thebault, E.; Huber, V.; Loreau, M. Cascading extinctions and ecosystem functioning: contrasting effects of diversity depending on food web structure. Oikos 2007, 116, 163-173.

26. Hillebrand, H.; Shurin, J.B. Biodiversity and aquatic food webs. In Aquatic Food Webs: An Ecosystem Approach; Belgrano, A., Scharler, U.M., Dunne, J., Ulanowicz, R.E., Eds.; Oxford University Press: Oxford, UK, 2005; pp. 183-198.

27. Dyer, L.A. The ecology of tri-trophic interactions in the tropics. In Tropical Forest Community Ecology; Carson, W.P., Schnitzer, S.A., Eds.; Blackwell Publishing: Oxford, UK, 2008.

28. Pearson, C.V.; Dyer, L.A. Trophic diversity in two grassland ecosystems. J. Insect Sci. 2006, doi: 10.1673/2006_06_25.1.

29. Schmitz, O.J. Predators have large effects on ecosystem properties by changing plant diversity, not plant biomass. Ecology 2006, 87, 1432-1437.

30. Sinclair, A.R.E.; Mduma, S.; Brashares, J.S. Patterns of predation in a diverse predator-prey system. Nature 2003, 425, 288-290.

31. Abrams, P.A. Trait-initiated indirect effects due to changes in consumption rates in simple food webs. Ecology 2004, 85, 1029-1038.

32. Menge, B.A. Detection of direct versus indirect effects: Were experiments long enough? Am. Nat. 1997, 149, 801-823.

33. Crowder, D.W.; Northfield, T.D.; Strand, M.R.; Snyder, W.E. Organic agriculture promotes evenness and natural pest control. Nature 2010, 466, 109-113.

34. Polis, G.A.; Strong, D.R. Food web complexity and community dynamics. Am. Nat. 1996, 147, 813-846.

35. Menge, B.A. Top-down and bottom-up community regulation in marine rocky intertidal habitats. J. Exp. Mar. Biol. Ecol. 2000, 250, 257-289. 
36. Halaj, J.; Wise, D.H. Terrestrial trophic cascades: How much do they trickle? Am. Nat. 2001, 157, 262-281.

37. Shurin, J.B.; Borer, E.T.; Seabloom, E.W.; Anderson, K.; Blanchette, C.A.; Broitman, B.; Cooper, S.D.; Halpern, B.S. A cross-ecosystem comparison of the strength of trophic cascades. Ecol. Lett. 2002, 5, 785-791.

38. Shurin, J.B.; Gruner, D.S.; Hillebrand, H. All wet or dried up? Real differences between aquatic and terrestrial food webs. Proc. R. Soc. B 2006, 273, 1-9.

39. Borer, E.T.; Seabloom, E.W.; Shurin, J.B.; Anderson, K.E.; Blanchette, C.A.; Broitman, B.; Cooper, S.D.; Halpern, B.S. What determines the strength of a trophic cascade? Ecology 2005, 86, 528-537.

40. Hunter, M.D. Multiple approaches to estimating the relative importance of top-down and bottom-up forces on insect populations: Experiments, life tables, and time-series analysis. Basic Appl. Ecol. 2001, 2, 295-309.

41. Terborgh, J.; Lopez, L.; Nunez, P.; Rao, M.; Shahabuddin, G.; Orihuela, G.; Riveros, M.; Ascanio, R.; Adler, G.H.; Lambert, T.D.; et al. Ecological meltdown in predator-free forest fragments. Science 2001, 294, 1923-1926.

42. Hillebrand, H.; Bennett, D.M.; Cadotte, M.W. Consequences of dominance: A review of evenness effects on local and regional ecosystem processes. Ecology 2008, 89, 1510-1520.

43. Schmitz, O.J.; Hamback, P.A.; Beckerman, A.P. Trophic cascades in terrestrial systems: A review of the effects of carnivore removals on plants. Am. Nat. 2000, 155, 141-153.

44. Bell, T.; Neill, W.E.; Schluter, D. The effect of temporal scale on the outcome of trophic cascade experiments. Oecologia 2003, 134, 578-586.

45. Knight, T.M.; Chase, J.M.; Hillebrand, H.; Holt, R.D. Predation on mutualists can reduce the strength of trophic cascades. Ecol. Lett. 2006, 9, 1173-1178.

46. Duffy, J.E.; Cardinale, B.J.; France, K.E.; McIntyre, P.B.; Thebault, E.; Loreau, M. The functional role of biodiversity in ecosystems: Incorporating trophic complexity. Ecol. Lett. 2007, 10, 522-538.

47. Reiss, J.; Bridle, J.R.; Montoya, J.M.; Woodward, G. Emerging horizons in biodiversity and ecosystem functioning research. Trends Ecol. Evol. 2009, 24, 505-514.

48. Strauss, S.Y.; Lau, J.A.; Schoener, T.W.; Tiffin, P. Evolution in ecological field experiments: Implications for effect size. Ecol. Lett. 2008, 11, 199-207.

49. Oksanen, L.; Fretwell, S.; Arruda, J.; Niemela, P. Exploitation ecosystems in gradients of primary productivity. Am. Nat. 1981, 118, 240-261.

50. Hunter, M.D.; Price, P.W. Playing chutes and ladders: Heterogeneity and the relative roles of bottom-up and top-down forces in natural communities. Ecology 1992, 73, 724-732.

51. Fretwell, S.D. The regulation of plant communities by food chains exploiting them. Perspect. Biol. Med. 1977, 20, 169-185.

52. Fretwell, S.D. Food chain dynamics: The central theory of ecology? Oikos 1987, 50, 291-301.

53. Oksanen, L. Trophic levels and trophic dynamics: A consensus emerging? Trends Ecol. Evol. 1991, 6, 58-60.

54. Hairston, J.; Hairston, S. Cause-effect relationships in energy flow, trophic structure, and interspecific interactions. Am. Nat. 1997, 142, 379-411. 
55. Rohde, K. Latitudinal gradients in species diversity: The search for the primary cause. Oikos 1992, 65, 514-527.

56. Waide, R.B.; Willig, M.R.; Steiner, C.F.; Mittelbach, G.; Gough, L.; Dodson, S.I.; Juday, G.P.; Parmenter, R. The relationship between productivity and species richness. Annu. Rev. Ecol. Syst. 1999, 30, 257-300.

57. Mittelbach, G.G.; Steiner, C.F.; Scheiner, S.M.; Gross, K.L.; Reynolds, H.L.; Waide, R.B.; Willig, M.R.; Dodson, S.I.; Gough, L. What is the observed relationship between species richness and productivity? Ecology 2001, 82, 2381-2396.

58. Arita, H.T.; Vazquez-Dominguez, E. The tropics: cradle, museum or casino? A dynamic null model for latitudinal gradients of species diversity. Ecol. Lett. 2008, 11, 653-663.

59. MacArthur, R.H. Species packing and competitive equilibrium for many species. Theor. Popul. Biol. 1970, $1,1-11$.

60. May, R.M. Stability and Complexity in Model Ecosystems; Princeton University Press: Princeton, NJ, USA, 1973.

61. Chesson, P. Mechanisms of maintenance of species diversity. Annu. Rev. Ecol. Syst. 2000, 31, 343-366.

62. Brandle, M.; Amarell, U.; Auge, H.; Klotz, S.; Brandl, R. Plant and insect diversity along a pollution gradient: Understanding species richness across trophic levels. Biodivers. Conserv. 2001, 10, 1497-1511.

63. Pearson, C.V.; Massad, T.J.; Dyer, L.A. Diversity cascades in alfalfa fields: From plant quality to agroecosystem diversity. Environ. Entomology 2008, 37, 947-955.

64. Schmied, A.; Fuhrer, E. The impact of ground beetle species (Coleoptera: Carabidae) in spruce stands, damaged by Pristiphora abietina (Hymenoptera: Tenthredinidae). Entomol. Gen. 1996, 21, 81-94.

65. Gruner, D.S.; Taylor, A.D. Richness and species composition of arboreal arthropods affected by nutrients and predators: A press experiment. Oecologia 2006, 147, 714-724.

66. Van der Heijden, M.G.A.; Klironomos, J.N.; Ursic, M.; Moutoglis, P.; Streitwolf-Engel, R.; Boller, T.; Wiemken, A.; Sanders, I.R. Mycorrhizal fungal diversity determines plant biodiversity, ecosystem variability and productivity. Nature 1998, 396, 69-72.

67. Eveleigh, E.S.; McCann, K.S.; McCarthy, P.C.; Pollock, S.J.; Lucarotti, C.J.; Morin, B.; McDougall, G.A.; Strongman, D.B.; Huber, J.T.; Umbanhowar, J.; et al. Fluctuations in density of an outbreak species drive diversity cascades in food webs. Proc. Natl. Acad. Sci. USA 2007, 104, 16976-16981.

68. Crutsinger, G.M.; Collins, M.D.; Fordyce, J.A.; Gompert, Z.; Nice, C.C.; Sanders, N.J. Plant genotypic diversity predicts community structure and governs an ecosystem process. Science 2006, 313, 966-968.

69. Wimp, G.M.; Wooley, S.; Bangert, R.K.; Young, W.P.; Martinsen, G.D.; Keim, P.; Rehill, B.; Lindroth, R.L.; Whitham, T.G. Plant genetics predicts intra-annual variation in phytochemistry and arthropod community structure. Mole. Ecol. 2007, 16, 5057-5069.

70. Strong, D.R.; Lawton, J.H.; Southwood, T.R.E. Insects on Plants: Community Patterns and Mechanisms; Harvard University Press: Cambridge, MA, USA, 1984. 
71. Rudgers, J.A.; Clay, K. An invasive plant-fungal mutualism reduces arthropod diversity. Ecol. Lett. 2008, 11, 831-840.

72. Boege, K.; Marquis, R.J. Plant quality and predation risk mediated by plant ontogeny: consequences for herbivores and plants. Oikos 2006, 115, 559-572.

73. Srivastava, D.S.; Vellend, M. Biodiversity-ecosystem function research: Is it relevant to conservation? Annu. Rev. Ecol. Evol. Syst. 2005, 36, 267-294.

74. Letourneau, D.K.; Jedlicka, J.A.; Bothwell, S.G.; Moreno, C.R. Effects of Natural Enemy Biodiversity on the Suppression of Arthropod Herbivores in Terrestrial Ecosystems. Ecol. Evol. Syst. 2009, 40, 573-592.

75. Hochberg, M.E. Consequences for host population levels of increasing natural enemy species richness in classical biological control. Am. Nat. 1996, 147, 307-318.

76. Denoth, M.; Frid, L.; Myers, J.H. Multiple agents in biological control: improving the odds? Biol. Control 2002, 24, 20-30.

77. Stireman, J.O.; Dyer, L.A.; Matlock, R.B. Top-down forces in managed versus unmanaged habitats. In Ecology of Predator-Prey Interactions; Barbosa, P., Castellanos, I., Eds.; Oxford University Press: Oxford, UK, 2004; pp. 303-323.

78. Otto, S.B.; Berlow, E.L.; Rank, N.E.; Smiley, J.; Brose, U. Predator diversity and identity drive interaction strength and trophic cascades in a food web. Ecology 2008, 89, 134-144.

79. Cardinale, B.J.; Srivastava, D.S.; Duffy, J.E.; Wright, J.P.; Downing, A.L.; Sankaran, M.; Jouseau, C. Effects of biodiversity on the functioning of trophic groups and ecosystems. Nature 2006, 443, 989-992.

80. Cardinale, B.J.; Harvey, C.T.; Gross, K.; Ives, A.R. Biodiversity and biocontrol: Emergent impacts of a multi-enemy assemblage on pest suppression and crop yield in an agroecosystem. Ecol. Lett. 2003, 6, 857-865.

81. Schmitz, O.J. Top predator control of plant biodiversity and productivity in an old-field ecosystem. Ecol. Lett. 2003, 6, 156-163.

82. Schmitz, O.J. Effects of predator hunting mode on grassland ecosystem function. Science 2008, 319, 952-954.

83. Letourneau, D.K.; Dyer, L.A. Experimental test in lowland tropical forest shows top-down effects through four trophic levels. Ecology 1998, 79, 1678-1687.

84. Letourneau, D.K.; Dyer, L.A. Density patterns of Piper ant-plants and associated arthropods: Top predator cascades in a terrestrial system? Biotropica 1998, 30, 162-169.

85. Letourneau, D.K.; Dyer, L.A.; Vega, G.C. Indirect effects of a top predator on a rain forest understory plant community. Ecology 2004, 85, 2144-2152.

86. Holt, R.D. Predation, apparent competition and the structure of prey communities. Theor. Popul. Biol. 1977, 12, 197-229.

87. Letourneau, D.K.; Armbrecht, I.; Rivera, B.S.; Lerma, J.M.; Carmona, E.J.; Daza, M.C.; Escobar, S.; Galindo, V.; Gutierrez, C.; Lopez, S.D.; et al. Does plant diversity benefit agroecosystems? A synthetic review. Ecol. Appl. 2011, 21, 9-21.

88. Stachowicz, J.J.; Bruno, J.F.; Duffy, J.E. Understanding the effects of marine biodiversity on communities and ecosystems Annu. Rev. Ecol. Evol. Syst. 2007, 38, 739-766. 
89. Losey, J.E.; Denno, R.F. Factors facilitating synergistic predation: The central role of synchrony. Ecol. Appl. 1999, 9, 378-386.

90. Losey, E.; Denno, R.F. Interspecific variation in the escape responses of aphids: Effect on risk of predation from foliar-foraging and ground-foraging predators. Oecologia 1998, 115, 245-252.

91. Yachi, S.; Loreau, M. Biodiversity and ecosystem productivity in a fluctuating environment: The insurance hypothesis. Proc. Natl. Acad. Sci. USA 1999, 96, 1463-1468.

92. Ives, A.R.; Klug, J.L.; Gross, K. Stability and species richness in complex communities. Ecol. Lett. 2000, 3, 399-411.

93. Soluk, D.A.; Collins, N.C. Synergistic Interactions Between Fish and Stoneflies Facilitation and Interference Among Stream Predators. Oikos 1988, 52, 94-100.

94. Jonsson, M.; Malmqvist, B. Mechanisms behind positive diversity effects on ecosystem functioning: Testing the facilitation and interference hypotheses. Oecologia 2003, 134, 554-559.

95. Cardinale, B.J.; Palmer, M.A.; Collins, S.L. Species diversity enhances ecosystem functioning through interspecific facilitation. Nature 2002, 415, 426-429.

96. Ives, A.R.; Murray, D.L. Can sublethal parasitism destabilize predator-prey population dynamics? A model of snowshoe hares, predators and parasites. J. Anim. Ecol. 1997, 66, 265-278.

97. Quicke, D.L.J. Parasitic Wasps; Chapman \& Hall: London, UK, 1997.

98. Siemann, E.; Tilman, D.; Haarstad, J.; Ritchie, M. Experimental tests of the dependence of arthropod diversity on plant diversity. Am. Nat. 1998, 152, 738-750.

99. Bukovinszky, T.; van Veen, F.J.F.; Jongema, Y.; Dicke, M. Direct and indirect effects of resource quality on food web structure. Science 2008, 319, 804-807.

100. Siemann, E. Experimental tests of effects of plant productivity and diversity on grassland arthropod diversity. Ecology 1998, 79, 2057-2070.

101. Feeley, K.J.; Terborgh, J.W. Direct versus indirect effects of habitat reduction on the loss of avian species from tropical forest fragments. Anim. Conserv. 2008, 11, 353-360.

102. Root, R.B. Organization of a plant-arthropod association in simple and diverse habitats: The fauna of collards (Brassica oleracea). Ecol. Monogr. 1973, 43, 95-124.

103. Gurr, G.M.; Van Emden, H.F.; Wratten, S.D. Habitat manipulation and natural enemy efficiency implications for the control of pests. In Conservation Biological Control; Barbosa, P., Ed.; Academic Press: San Diego, CA, USA, 1998; pp. 155-184.

104. Rosenheim, J.A.; Wilhoit, L.R.; Armer, C.A. Influence of intraguild predation among generalist insect predators on the suppression of an herbivore population. Oecologia 1993, 96, 439-449.

105. Kruess, A.; Tscharntke, T. Species richness and parasitism in a fragmental landscape: Experiments and field studies with insects on Vicia sepium. Oecologia 2000, 122, 129-137.

106. Snyder, W.E.; Ives, A.R. Generalist predators disrupt biological control by a specialist parasitoid. Ecology 2001, 82, 705-716.

107. Snyder, W.E.; Wise, D.H. Contrasting trophic cascades generated by a community of generalist predators. Ecology 2001, 82, 1571-1583.

108. Persad, A.B.; Hoy, M.A. Predation by Solenopsis invicta and Blattella asahinai on Toxoptera citricida parasitized by Lysiphlebus testaceipes and Lipolexis oregmae on citrus in Florida. Biol. Control 2004, 30, 531-537. 
109. Philpott, S.M.; Maldonado, J.; Vandermeer, J.; Perfecto, I. Taking trophic cascades up a level: Behaviorally-modified effects of phorid flies on ants and ant prey in coffee agroecosystems. Oikos 2004, 105, 141-147.

110. Rosenheim, J.A.; Glik, T.E.; Goeriz, R.E.; Ramert, B. Linking a predator's foraging behavior with its effects on herbivore population suppression. Ecology 2004, 85, 3362-3372.

111. Snyder, W.E.; Snyder, G.B.; Finke, D.L.; Straub, C.S. Predator biodiversity strengthens herbivore suppression. Ecol. Lett. 2006, 9, 789-796.

112. Letourneau, D.K.; Bothwell, S.G. Comparison of organic and conventional farms: Challenging ecologists to make biodiversity functional. Front. Ecol. Environ. 2008, 6, 430-438.

113. Mills, N.J.; Kenis, M. A Study of the Parasitoid Complex of the European Fir Budworm, Choristoneura murinana (Lepidoptera, Tortricidae), and Its Relevance for Biological-Control of Related Hosts. Bull. Entomol. Res. 1991, 81, 429-436.

114. Compton, S.G.; Hawkins, B.A. Determinants of species richness in southern african fig wasp assemblages. Oecologia 1992, 91, 68-74.

115. Russell, E.P. Enemies hypothesis-A review of the effect of vegetational diversity on predatory insects and parasitoids. Environ. Entomol. 1989, 18, 590-599.

116. Letourneau, D.K. Plant-arthropod interactions in agroecosystems. In Agricultural ecology; Jackson, L.E., Ed.; Academic Press: New York, NY, USA, 1997; pp. 239-290.

117. Ale, S.B.; Whelan, C.J. Reappraisal of the role of big, fierce predators! Biodivers. Conserv. 2008, 17, 685-690.

118. Keesing, F.; Holt, R.D.; Ostfeld, R.S. Effects of species diversity on disease risk. Ecol. Lett. 2006, 9, 485-498.

119. Carlson, J.C.; Dyer, L.A.; Omlin, F.X.; Beier, J.C. Diversity cascades and malaria vectors. J. Med. Entomol. 2009, 46, 460-464.

120. Ostfeld, R.S.; Keesing, F. Biodiversity and disease risk: The case of lyme disease. Conserv. Biol. 2000, 14, 722-728.

121. Logiudice, K.; Duerr, S.T.K.; Newhouse, M.J.; Schmidt, K.A.; Killilea, M.E.; Ostfeld, R.S. Impact of host community composition on lyme disease risk. Ecology 2008, 89, 2841-2849.

122. Gilman, S.E.; Urban, M.C.; Tewksbury, J.; Gilchrist, G.W.; Holt, R.D. A framework for community interactions under climate change. Trends Ecol. Evol. 2010, 25, 325-331.

123. Araujo, M.B.; Luoto, M. The importance of biotic interactions for modelling species distributions under climate change. Global Ecol. Biogeogr. 2007, 16, 743-753.

124. Bannerman, J.A.; Gillespie, D.R.; Roitberg, B.D. The impacts of extreme and fluctuating temperatures on trait-mediated indirect aphid-parasitoid interactions. Ecol. Entomol. 2011, 36, 490-498.

125. Lurgi, M.; Lopez, B.C.; Montoya, J.M. Novel communities from climate change. Phil. Trans. R. Soc. B 2012, 367, 2913-2922.

126. Lurgi, M.; Lopez, B.C.; Montoya, J.M. Climate change impacts on body size and food web structure on mountain ecosystems. Phil. Trans. R. Soc. B 2012, 367, 3050-3057.

127. Gillespie, D.R.; Nasreen, A.; Moffat, C.E.; Clarke, P.; Roitberg, B.D. Effects of simulated heat waves on an experimental community of pepper plants, green peach aphids and two parasitoid species. Oikos 2012, 121, 149-159. 
128. De Sassi, C.; Tylianakis, J.M. Climate change disproportionately increases herbivore over plant or parasitoid biomass. PloS One 2012, 7, e40557.

129. Brose, U.; Dunne, J.A.; Montoya, J.M.; Petchey, O.L.; Schneider, F.D.; Jacob, U. Climate change in size-structured ecosystems Introduction. Phil. Trans. R. Soc. B 2012, 367, 2903-2912.

130. Harrington, R.; Woiwod, I.; Sparks, T. Climate change and trophic interactions. Trends Ecol. Evol. 1999, 14, 146-149.

131. Kratina, P.; Greig, H.S.; Thompson, P.L.; Carvalho-Pereira, T.S.A.; Shurin, J.B. Warming modifies trophic cascades and eutrophication in experimental freshwater communities. Ecology 2012, 93, 1421-1430.

132. Petchey, O.L.; McPhearson, P.T.; Casey, T.M.; Morin, P.J. Environmental warming alters foodweb structure and ecosystem function. Nature 1999, 402, 69-72.

133. Traill, L.W.; Lim, M.L.M.; Sodhi, N.S.; Bradshaw, C.J.A. Mechanisms driving change: Altered species interactions and ecosystem function through global warming. J. Anim. Ecol. 2010, 79, 937-947.

134. Harmon, J.P.; Moran, N.A.; Ives, A.R. Species response to environmental change: Impacts of food web interactions and evolution. Science 2009, 323, 1347-1350.

135. Hoekman, D. Turning up the heat: Temperature influences the relative importance of top-down and bottom-up effects. Ecology 2010, 91, 2819-2825.

136. Merrill, R.M.; Gutierrez, D.; Lewis, O.T.; Gutierrez, J.; Diez, S.B.; Wilson, R.J. Combined effects of climate and biotic interactions on the elevational range of a phytophagous insect. J. Anim. Ecol. 2008, 77, 145-155.

137. Voigt, W.; Perner, J.; Jones, T.H. Using functional groups to investigate community response to environmental changes: Two grassland case studies. Global Change Biol. 2007, 13, 1710-1721.

138. Binzer, A.; Guill, C.; Brose, U.; Rall, B.C. The dynamics of food chains under climate change and nutrient enrichment. Phil. Trans. R. Soc. B 2012, 367, 2935-2944.

139. De Sassi, C.; Lewis, O.T.; Tylianakis, J.M. Plant-mediated and nonadditive effects of two global change drivers on an insect herbivore community. Ecology 2012, 93, 1892-1901.

140. Jeffs, C.T.; Lewis, O.T. Effects of climate warming on hostparasitoid interactions. Ecol. Entomol.2013, $38,209-218$.

141. Newman, J.A. Climate change and cereal aphids: the relative effects of increasing $\mathrm{CO}_{2}$ and temperature on aphid population dynamics. Global Change Biol. 2004, 10, 5-15.

142. Tylianakis, J.M.; Didham, R.K.; Bascompte, J.; Wardle, D.A. Global change and species interactions in terrestrial ecosystems. Ecol. Lett. 2008, 11, 1351-1363.

143. Zvereva, E.L.; Kozlov, M.V. Consequences of simultaneous elevation of carbon dioxide and temperature for plant-herbivore interactions: A metaanalysis. Global Change Biol. 2006, 12, $27-41$.

144. Shurin, J.B.; Clasen, J.L.; Greig, H.S.; Kratina, P.; Thompson, P.L. Warming shifts top-down and bottom-up control of pond food web structure and function. Phil. Trans. R. Soc. B 2012, 367, 3008-3017.

145. O'Connor, M.I.; Gilbert, B.; Brown, C.J. Theoretical predictions for how temperature affects the dynamics of interacting herbivores and plants. Am. Nat. 2011, 178, 626-638.

146. Petchey, O.L.; Brose, U.; Rall, B.C. Predicting the effects of temperature on food web connectance. Phil. Trans. R. Soc. B 2010, 365, 2081-2091. 
147. De Sassi, C.; Staniczenko, P.P.A.; Tylianakis, J.M. Warming and nitrogen affect size structuring and density dependence in a host-parasitoid food web. Phil. Trans. R. Soc. B 2012, 367, 3033-3041.

148. Hoover, J.K.; Newman, J.A. Tritrophic interactions in the context of climate change: A model of grasses, cereal Aphids and their parasitoids. Global Change Biol. 2004, 10, 1197-1208.

149. Hance, T.; van Baaren, J.; Vernon, P.; Boivin, G. Impact of extreme temperatures on parasitoids in a climate change perspective. Annu. Rev. Entomol. 2007, 52, 107-126.

150. Stireman, J.O.; Dyer, L.A.; Janzen, D.H.; Singer, M.S.; Li, J.T.; Marquis, R.J.; Ricklefs, R.E.; Gentry, G.L.; Hallwachs, W.; Coley, P.D.; et al. Climatic unpredictability and parasitism of caterpillars: Implications of global warming. Proc. Natl. Acad. Sci. USA 2005, 102, 17384-17387.

151. Dyer, L.A.; Richards, L.A.; Short, S.A.; Dodson, C.D. Effects of $\mathrm{CO}_{2}$ and temperature on tritrophic interactions. PloS One 2013, 8, e62528.

152. Massad, T.J.; Dyer, L.A. A meta-analysis of the effects of global environmental change on plant-herbivore interactions. Arthropod-Plant Int. 2010, 4, 181-188.

153. Holt, R.D.; Polis, G.A. A theoretical framework for intraguild predation. Am. Nat. 1997, 149, $745-764$.

154. Ostfeld, R.S.; Holt, R.D. Are predators good for your health? Evaluating evidence for top-down regulation of zoonotic disease reservoirs. Front. Ecol. Environ. 2004, 2, 13-20.

155. Novotny, V.; Basset, Y. Review-Host specificity of insect herbivores in tropical forests. Proc. $R$. Soc. B 2005, 272, 1083-1090.

156. Schoener, T.W.; Spiller, D.A. Devastation of prey diversity by experimentally introduced predators in the field. Nature 1996, 381, 691-694.

157. Krebs, C.J.; Boutin, S.; Boonstra, R.; Sinclair, A.R.E.; Smith, J.N.M.; Dale, M.R.T.; Martin, K.; Turkington, R. Impact of food and predation on the snowshoe hare cycle. Science 1995, 269, $1112-1115$.

158. Krebs, C.J.; Boonstra, R.; Boutin, S.; Sinclair, A.R.E. What drives the 10 -year cycle of snowshoe haves? Bioscience 2001, 51, 25-35.

159. Bascompte, J.; Jordano, P.; Melian, C.J.; Olesen, J.M. The nested assembly of plant-animal mutualistic networks. Proc. Natl. Acad. Sci. USA 2003, 100, 9383-9387.

160. Bascompte, J.; Jordano, P. Plant-animal mutualistic networks: The architecture of biodiversity. Ann. Rev. Ecol. Evol. Syst. 2007, 38, 567-593.

161. Dyer, L.A.; Singer, M.S.; Lill, J.T.; Stireman, J.O.; Gentry, G.L.; Marquis, R.J.; Ricklefs, R.E.; Greeney, H.F.; Wagner, D.L.; Morais, H.C.; et al. Host specificity of Lepidoptera in tropical and temperate forests. Nature 2007, 448, 696-699.

162. Staniczenko, P.P.A.; Kopp, J.C.; Allesina, S. The ghost of nestedness in ecological networks. Nat. Commun. 2013, doi: 10.1038/ncomms2422.

163. Hawkins, B.A.; Cornell, H.V.; Hochberg, M.E. Predators, parasitoids, and pathogens as mortality agents in phytophagous insect populations. Ecology 1997, 78, 2145-2152.

164. Dyer, L.A.; Letourneau, D.K. Relative strengths of top-down and bottom-up forces in a tropical forest community. Oecologia 1999, 119, 265-274. 
165. O'Dowd, D.J.; Green, P.T.; Lake, P.S. Invasional 'meltdown' on an oceanic island. Ecol. Lett. 2003, 6, 812-817.

(C) 2013 by the authors; licensee MDPI, Basel, Switzerland. This article is an open access article distributed under the terms and conditions of the Creative Commons Attribution license (http://creativecommons.org/licenses/by/3.0/). 